\title{
O Olhar Fronteiriço da Memória pela Perspectiva de Bergson e Halbwachs ${ }^{1}$
}

\author{
The Border View of Memory From The Perspective of Bergson and \\ Halbwachs
}

\author{
ODILENE SILVA DO NASCIMENTO ALMEIDA \\ Universidade Estadual do Maranhão (UEMA). \\ odilenealmeida16@gmail.com
}

\begin{abstract}
RESUMO
O presente estudo apresenta uma abordagem integrativa da literatura a respeito da memória, tendo como eixo norteador as teorias de Henri Bergson e Maurice Halbwachs. A pesquisa é fruto da experiência obtida pelo intercâmbio discente, ocorrido na Universidade Estadual do Sudoeste da Bahia - UESB, no âmbito do Programa de Cooperação Acadêmica na Amazônia - PROCAD. Para tanto, foram destacadas as principais características que fomentam a discussão sobre a memória, a partir das abordagens levantadas pelos dois teóricos em foco, durante a realização das disciplinas. Nesse intento, é de suma importância entender que, a memória agrega uma gama de circunstâncias e aspectos relevantes para o ato rememorativo, sofrendo influências do espaço, linguagem, história, percepção, dentre tantos outros, variando conforme a significação dada por cada estudioso.
\end{abstract}

Palavras-chave: Memória. Bergson. Halbwachs.

\begin{abstract}
The present study presents an integrative approach of the literature regarding memory, having the theories of Henri Bergson and Maurice Halbwachs as a guiding axis. The research is the result of the experience gained by the student exchange, which took place at the State University of Southwestern Bahia - UESB, within the scope of the Academic Cooperation Program in the Amazon - PROCAD. For that, the main characteristics that foster the discussion about memory were highlighted, from the approaches raised by the two theorists in focus, during the realization of the disciplines. In this attempt, it is of utmost importance to understand that, memory adds a range of circumstances and relevant aspects for the remembrance act, suffering influences from space, language, history, perception, among many others, varying according to the meaning given by each scholar.
\end{abstract}

Keywords: Memory. Bergson. Halbwachs.

\section{INTRODUÇÃO}

A memória é pautada por uma série de compreensões discutidas nos mais diversos âmbitos do conhecimento, sendo popularmente relacionada com a volta ao passado. Porém, é de suma importância entender que o processo que envolve a rememoração internaliza aspectos bem mais complexos, levantando indagações a todo instante em detrimento das

\footnotetext{
${ }^{1}$ Artigo submetido para avaliação em 20/04/2021 e aprovado em 30/04/2021.
} 
Rev. Interd. em Cult. e Soc. (RICS), São Luís, v. 7, n. 1, p. 14- 27, jan./jun. 2021

ISSN eletrônico: 2447-6498

relações que é capaz de estabelecer, seja com o ambiente, o indivíduo, como também aspectos sociais, ideológicos, históricos e assim por diante.

Os estudos sobre os aspectos da memória evidenciam uma conjuntura de relação intrínseca entre os elementos que a recompõem. Nesse viés, a sociedade depreende formas particulares de recordação, constituídas por relações diretas ou indiretas com os demais sujeitos que fazem parte do contexto social, sobretudo, de um universo marcado pelos questionamentos constantes, tendo como base a busca por respostas no passado. A memória, assim, pode ser compreendida a partir das influências das mais variadas correntes de pensamento, bem como de marcos que absorvem uma conduta reflexiva, por meio de um processo interativo.

Ante o exposto, o presente estudo fomenta a reflexão acerca das discussões pertinentes ao viés memorialístico, como fruto da experiência do intercâmbio discente na Universidade Estadual do Sudoeste da Bahia - UESB, realizado no período de julho a setembro de 2019. $\mathrm{Na}$ oportunidade, foram cursadas as disciplinas: Memória em Bergson e Memória em Halbwachs, ambas intensivas, em consonância com o Programa de Pós-Graduação em Memória: linguagem e sociedade, da referida instituição, no campus de Vitória da Conquista - BA.

É interessante frisar que a experiência é oriunda do Programa de Cooperação Acadêmica na Amazônia - PROCAD, que mantém cooperação entre a Universidade Estadual do Sudoeste da Bahia - UESB, a Universidade Estadual do Maranhão - UEMA e Universidade Federal do Maranhão - UFMA. Por meio do programa, professores e alunos pesquisadores adquirem conhecimento acerca de seus objetos de pesquisa, temáticas variáveis dentro da esfera memorialística, bem como trocam informações relevantes para o enriquecimento de sua caminhada acadêmica.

Diante disso, o estudo apresenta uma breve discussão sobre a memória, traçando as condições e pressupostos que correspondem ao campo de abordagem especificado nas disciplinas cursadas. Parte, então, da concepção de Bergson, dando ênfase à percepção da imagem - movimento, e de Halbwachs ao tratar da memória relacionada ao espaço e à linguagem.

É notório que a busca pela memória permeia um universo rico e plural, transmutado por entendimentos diversos em torno de sua manifestação. A respeito, surgem teorias e demais estudos que oportunizam a discussão em foco, desencadeando a necessidade de atualização constante em prol da reflexão memorialística. 
Rev. Interd. em Cult. e Soc. (RICS), São Luís, v. 7, n. 1, p. 14- 27, jan./jun. 2021 ISSN eletrônico: 2447-6498

O passado coexiste no presente, de tal forma que sua interferência é modificada e operacionalizada de acordo com situações amplas no contexto social. Cada estudioso apresenta uma tese pautada nas suas convicções e experiências, traçando uma via de mão dupla entre a busca do conhecimento e a reprodução de linhas de pensamento que ora aproxima, ora distancia seus fundamentos básicos com os estudos já existentes.

\section{A MEMÓRIA PELA ÓTICA DE BERGSON}

Henri Bergson figura como um dos mais importantes estudiosos do campo da memória, seus postulados tratam de questões pertinentes sobre o processo rememorativo e suas implicações. A linha de pensamento do teórico, oportuniza a reflexão em torno da memória enquanto passado consolidado no presente, proposto por uma fluência desencadeada nas imagens que envolvem o ser. Essa realidade pode ser disposta pelo contato com as experiências e hábitos, atrelados pelas marcas que ficaram e são revividas a partir de um novo contexto, mas que levam ao mesmo lugar de origem, o passado.

Diante da tese de Bergson em Matéria e memória (1999), o caráter memorialístico é determinado pela noção de diferença, seus componentes coadunam com uma perspectiva alicerçada numa realidade para além do espírito e da matéria. A diferença, aqui, está condicionada pela maneira que o teórico apresenta sua tese, mantendo forte relação entre as visões metodológica, cosmológica e ontológica. Isso se dá pelo contato com uma abordagem memorialística mais próxima do âmbito abstrato ou virtual.

Do mesmo modo, a dinâmica do passado - presente - futuro é depreendida por uma lógica múltipla, deixando o caminho aberto para a reconfiguração das lembranças que chegam de forma impactante no indivíduo. Assim, a retomada ao passado é um mecanismo que é constituído em prol da experiência do momento atual, relacionada com todos os aspectos que se articulam a esse contexto.

A concepção de Bergson sobre a memória, estabelece que ela é regida também pelo poder das influências, implicando dizer que o ser humano se volta para o passado de maneira tão intensa e complexa, que as características desse devir ocorrem como prolongamento das experiências, como se aquilo que é vivenciado no presente, nada mais é que, o resultado desse amadurecimento em si mesmo.

O teórico reflete sobre o que ele chama de reconhecimento por imagem, ou seja, o objeto a ser servido, ou ainda, o atendimento de demandas. Cada indivíduo faz um caminho pautado na necessidade de reviver aquilo que foi passado, tendo em vista que os fundamentos 
Rev. Interd. em Cult. e Soc. (RICS), São Luís, v. 7, n. 1, p. 14- 27, jan./jun. 2021 ISSN eletrônico: 2447-6498

que o cercam são denotativos das transformações ocorridas ao longo de sua trajetória. O ser recorda por um motivo, a fim de atender a uma necessidade individual, de ordem psicológica.

A memória advém, então, de uma relação intrínseca ao estado da percepção, ou seja, são elementos considerados como inseparáveis (BERGSON, 1999). Nesse intento, o caráter memorialístico ocorre pela necessidade de tomada de decisão, de ir buscar no passado as respostas para as decisões firmadas no presente. Não se trata de resgatar o que passou, mas de compreender as situações de outrora que refletem em momentos distintos da vida.

Em O conceito de memória na obra Matéria e Memória, de Henri Bergson (2012), de Joaquim Francisco Guimarães, é possível identificar de maneira clara a importância dada à percepção, diante da relação que mantém com o processo de assimilação das lembranças. As imagens formam uma espécie de corpo que equivale ao contato com a experiência imediata, com a necessidade de perceber aquilo que rodeia o ser no ato rememorativo.

A percepção da memória ultrapassa o simples contato com o objeto presente, a matéria figura como representação isolada da lembrança produzida, numa espécie de encarnação (GUIMARÃES et al., 2012). Isso denota a urgência em compreender acerca dos limites que são impostos ao caráter rememorativo, haja vista que sua fruição desemboca numa concepção bem mais complexa do que a retomada. É algo inalterável, mas que permanece no inconsciente de maneira unívoca.

Para além da matéria, Bergson discute a força que a representação da realidade é disposta por meio dos elementos que permeiam as lembranças, sendo estas relevantes para cada contexto de realização em específico. O indivíduo, assim, descarta as lembranças que não fazem sentido, tomando para si aquelas que fomentam uma visão necessária e importante em sua vida.

A realidade da matéria consiste na totalidade de seus elementos e de suas ações de todo tipo. Nossa representação da matéria é a medida de nossa ação possível sobre os corpos; ela resulta da eliminação daquilo que não interessa nossas necessidades e, de maneira mais geral, nossas funções. (BERGSON, 1999, p. 35-36)

Da relação entre a matéria e a realidade, é importante destacar a presença da subjetividade, a qual Bergson expressa por meio da análise das imagens exteriores. $\mathrm{O}$ indivíduo se apodera das imagens que compõem o lugar em que ocupa, culminando com a volta ao passado de forma a tentar recompor o cenário atual. É preciso rever as impressões de outrora, para trazer sentido para a realidade presente. 
Rev. Interd. em Cult. e Soc. (RICS), São Luís, v. 7, n. 1, p. 14- 27, jan./jun. 2021 ISSN eletrônico: 2447-6498

A memória também é exposta como equivalente à ideia de potência, dando margem para uma assimilação de que há uma força imanente, capaz de fomentar a reconstrução de um processo sobre suas origens, por meio da recordação e do reconhecimento de si. O passado, então, sobrevive por meio das imagens que o recompõem.

Se colocarmos a memória, isto é, uma sobrevivência das imagens passadas, estas imagens irão misturar-se constantemente à nossa percepção do presente e poderão inclusive substituí-la. Pois elas só se conservam para tornarem-se úteis: a todo instante completam a experiência presente enriquecendo-a com a experiência adquirida; e, como esta não cessa de crescer, acabará por recobrir e submergir a outra. (BERGSON, 1999, p. 69)

A forma como cada indivíduo recorda, as informações que são decorrentes desse processo, bem como a intensidade com a qual as lembranças são desencadeadas, tudo serve como aparato para a sobrevivência das imagens. É uma espécie de "seleção natural” daquilo que faz sentido, ou seja, a memória flui de uma ação marcada pelo estímulo presente.

Como decorrência dessa dinâmica em que a memória está inserida, é de suma importância entender que a mente, então, atua como conservação do que a matéria dissipa, de modo que o passado será sempre um fundamento constante, fazendo recorrência a ele de maneira frequente. A memória, assim, pode ser discernida por meio da realidade como filtro daquilo que é real, numa perspectiva que abrange interesses práticos.

O ser humano é dotado de faces sensoriais e motoras, para Bergson (1999) isso equivale às imagens percebidas pelo homem como apreensão da realidade que o cerca. $\mathrm{O}$ plano das imagens é concebido como movimento, de modo que o pensamento é a luz, disposta em mais abundância no mundo do que na própria consciência. Em igual circunstância, as imagens também compartilham dessa ideia de exteriorização, assemelhando-se a um processo paradoxal da contemporaneidade, o passado como determinante do presente.

Nesse contexto, Bergson (1999) propõe que a consciência humana pode ser considerada como apenas uma região na qual as imagens são formadas, constituindo um estado de representação das coisas e objetos. Com isso, a descrição de um objeto é apenas uma multiplicidade de aspectos, pautada em elementos quantitativos e qualitativos associados à duração, ou seja, a experiência psíquica.

Os conceitos que circundam a noção de memória também estão instituídos como perspectivas firmadas na temporalidade, haja vista que o mundo interno do ser humano é considerado temporal. A partir desse pressuposto, é pertinente ressaltar a ideia centrada no 
Rev. Interd. em Cult. e Soc. (RICS), São Luís, v. 7, n. 1, p. 14- 27, jan./jun. 2021

ISSN eletrônico: 2447-6498

caráter subjetivo do tempo, corroborando com a adoção de uma estrutura delineada pela experiência da duração.

Segundo Gilles Deleuze em Bergsonismo (1999), o tempo, na concepção de Bergson, surge como fundamento da mudança, na qual as imagens partem de uma esfera concretizada na realidade, para uma conjuntura expressada no plano da imaginação. Para tanto, o passado acaba sendo corroborado como imediato, abrindo espaço para a compreensão de abertura.

O indivíduo tem em sua vida, a fusão dos aspectos exteriores com o caráter de interioridade, tendo em vista a presença da memória por meio das imagens que o cercam. Isso pode ocorrer tanto no campo da materialidade, ou mesmo, da abstração, evocando uma espécie de retrospecto das situações marcantes que perpassou ao longo do seu caminho.

As percepções diversas do mesmo objeto que oferecem meus diversos sentidos não reconstituirão, portanto, ao se reunirem, a imagem completa do objeto; permanecerão separadas uma das outras por intervalos que medem, de certo modo, muitos vazios em minhas necessidades: é para preencher tais intervalos que uma educação dos sentidos é necessária (BERGSON, 1999, p. 49).

É perceptível um movimento entre as ideias, as lembranças e o momento que cerca o indivíduo. A rememoração compõe um cenário em constante adaptação, refletindo num caráter cíclico, no qual as imagens são percebidas enquanto variação da realidade por meio das experiências do passado. A percepção acaba servindo como medida para a materialização das lembranças, que nascem do contexto da virtualidade.

De tal modo, no que se refere à imagem como movimento, esta absorve uma relação de causa e efeito, de modo que o corpo atua como componente ativo na relação entre imagem e subjetividade (GUIMARÃES et al., 2012). Nesse ponto, é possível depreender que a memória surge através da recepção da imagem de caráter subjetivo, a partir do contato com o seu lugar de origem e as particularidades que dele são advindas.

A ideia de movimento também está associada com a ação voluntária produzida pelas imagens apreendidas pelo cérebro, e a memória desempenha o papel principal em todos os estados psicológicos (BERGSON, 1999). Os elementos considerados como exteriores partem, então, de uma prerrogativa de aproximação com o corpo, ou seja, a matéria enquanto desencadeadora dos sentidos no processamento do real. Associado a essa perspectiva e ao estado da matéria, Deleuze (1999, p. 24) expõe:

A matéria é efetivamente o "lado" pelo qual as coisas tendem a apresentar entre si e a nós mesmos tão-somente diferenças de grau. A experiência nos 
Rev. Interd. em Cult. e Soc. (RICS), São Luís, v. 7, n. 1, p. 14- 27, jan./jun. 2021 ISSN eletrônico: 2447-6498

propicia mistos; ora, o estado do misto não consiste apenas em reunir elementos que diferem por natureza, mas em reuni-los em condições tais que não podemos aprender nele essas diferenças de natureza constituintes.

Tomando por base esses pressupostos, é válido ressaltar que, o mundo é composto por imagens e a apreensão desse mundo se dá através do corpo. Esse importante processo de apreensão é constituído pelos movimentos desencadeados pela percepção das imagens, sendo propiciadoras de mecanismos imbricados na constância de combinações associativas com o campo da memória, em face de suas ações e projeções.

A partir disso, a imagem é consolidada pela representação das coisas em razão do espírito, da complexidade que norteia a totalidade de elementos configurativos da memória. Nesse intento, o indivíduo nutre suas lembranças de outrora como uma tentativa de contato com o devir, sobretudo, por meio do poder da influência pela imagem-movimento.

O ser humano tem a urgência em relembrar a todo instante, bem como em tentar compreender os traços de memória que fomentam sua experiência real. As imagens evocadas ilustram de forma profunda o seu passado, haja vista sua inquietude frente aos caminhos delineados ao longo do tempo. Com isso, o caráter memorialístico toma forma pelas percepções associadas a esse complexo conjunto de lembranças.

\section{A RELAÇÃo DA MEMÓRIA COM O ESPAÇO E A LINGUAGEM EM HALBWACHS}

A compreensão da memória pelo viés de Maurice Halbwachs remonta a fatores diversos dentro do contexto da rememoração, tendo em vista que sua natureza é traduzida pelo condensamento dos quadros sociais, instituídos por uma acepção de fenômenos necessariamente coletivos.

$\mathrm{Na}$ visão do teórico, não é possível discutir os processos memorialísticos sem ter contato com esses quadros, pois estes são configurados como alicerces primordiais quando o assunto parte dessa premissa. Existem vários critérios que permeiam a rememoração no plano individual, porém o seu clímax advém de um contexto no qual o fator social está inserido de forma arraigada, caminhando lado a lado com a linguagem e o espaço.

Tomando por base os estudos de Halbwachs em A memória coletiva (2006), as experiências correspondentes ao campo da memória se tornam plurais, partem de uma esfera de interesses próprios, mas ganham força a partir do contato com o universo exterior, característica essencial do homem, a sociabilidade. Sem o estabelecimento da linguagem, fica 
Rev. Interd. em Cult. e Soc. (RICS), São Luís, v. 7, n. 1, p. 14- 27, jan./jun. 2021 ISSN eletrônico: 2447-6498

difícil evocar as lembranças do passado, uma vez que a memória tem forte relação com a palavra, compreendida no cerne das questões integrantes de uma sociedade.

É a partir da linguagem que a memória se mantém viva, fazendo com que o sujeito que rememora seja envolto por uma tônica de transformação do eu com o outro, a manutenção de experiências coletivas que perpassam ao longo do tempo através do discurso correspondente e estabelecido pelos grupos.

Em Linguagem, memória e religião no pensamento de Maurice Halbwachs (2018), Dario Rivera expõe a forma como o teórico torna próxima a discussão entre a linguagem e o caráter memorialístico que compõem a sociedade. Para ele, é por meio da linguagem que as lembranças são evidenciadas no contato com as experiências, sendo então elemento de suma importância no processo rememorativo.

Os estudos de Halbwachs demonstram de um lado a estreita relação entre memória e linguagem; ao ponto de serem mutuamente dependentes. Sem linguagem não há memória possível, mas, sem memória, a linguagem também seria impossível. [...] Os limites da memória resultam também da riqueza da linguagem, capaz de adquirir múltiplas formas. (RIVERA, 2018, p. 1195)

Da dinâmica entre linguagem e memória, é notória a presença dos sonhos, pois estes figuram como elementos desencadeadores das reflexões de Halbwachs, tendo em vista que trata da forma como a memória se apropria do vivido, ou seja, em qual perspectiva esta acaba sendo materializada plenamente.

Na obra Los marcos sociales de la memoria (2004), Halbwachs abre espaço para questionamentos que pairam sobre a mente do ser que rememora. As suas impressões durante o estágio de inconsciência, o sonho, representa um campo fértil para a busca pela compreensão de como a realidade pode ser constituída nessa dinâmica absorta por um diacronismo eminente.

Si el sueño fuese, en realidad, el resultado de un encuentro y de un ensamblaje entre el recuerdo conservado tal como es en la memoria y de un comienzo de sensación, sería necesario que, durante el sueño, apareciesen unas imágenes que reconoceríamos como unos recuerdos, y no simplesmente aquellas de las que comprenderíamos el sentido (HALBWACHS, 2004, p. 66).

É nesse jogo de ideias e contrapontos que a linguagem ganha espaço considerável, pois dela resultam os traços provenientes da memória. Aquilo que é disposto no sonho não é constituído como realidade, pelo fato da linguagem não ser desencadeada como algo concreto 
Rev. Interd. em Cult. e Soc. (RICS), São Luís, v. 7, n. 1, p. 14- 27, jan./jun. 2021 ISSN eletrônico: 2447-6498

nesse momento. Sua manifestação ocorre por meio de uma arbitrariedade, porém, na esfera do universo real, sua presença é condicionante para a rememoração propriamente dita, considerando sua estrutura linear.

La memoria del hombre sumergido en el sueño no funciona con el mismo grado de precisión y no se encuentra en la capacidad de captar o assimilar conjuntos de recuerdos tan complejos, como em el caso de la memoria del hombre despierto que dispone de todas sus facultades intelectuales y, por ellas, puede apoyarse en la experiencia colectiva, mucho más estable y mejor organizada que la suya. (HALBWACHS, 2004, p. 79)

Ainda no que concerne à linguagem, "Halbwachs, em perspectiva mais sociológica, não se interessa pela linguagem em si mesma e sim pela relação com o pensamento social e com a memória coletiva" (RIVERA, 2018, p. 1178). Isso denota uma relevância evidente em seus estudos, haja vista que a memória é processada com base num conjunto de fatores, admitindo sentidos compartilhados com um contexto plural, e ao mesmo tempo, dinamizado pelas singularidades que cada indivíduo traz consigo.

O passado necessita de reconstrução através de um processo organizado e sistemático, fomentando uma reflexão sobre o contato com as lembranças, absorvendo uma ideia de continuidade daquilo que foi posto outrora (HALBWACHS, 2004). Quando se trata da linguagem enquanto aspecto preponderante da ação de rememorar, é sabido que as marcas do passado estão preservadas como testemunhos do que foi vivido. O registro, então, é dado tanto no contexto da escrita, quanto da oralidade, perpetuando a memória, e mantendo-a viva no grupo.

O homem não vive isolado, notadamente, sua expressão enquanto agente social presentifica essa concepção. É na linguagem que se encontram as marcas de um povo, de uma sociedade, bem como por meio dela é possível estabelecer os caminhos que condicionaram o percurso que o indivíduo traçou. As ações de cunho interacionais refletem a perspectiva de manutenção e abrigo da memória, haja vista que o ser sensível/racional produz significados a partir do contato com aquilo que corresponde ao seu passado.

É uma forma de tentar buscar respostas que não estão no presente, mas que, de algum modo, possuem relação de mutualidade entre épocas distintas da vida. A memória eis que surge como um alicerce das experiências e mantém viva, por meio da linguagem, os elementos indissociáveis da vida, conservada na mente de quem rememora.

Indo além da discussão, surge o espaço como elemento de abordagem. É possível depreender que sua forte presença remonta a uma série de questões envoltas pela concepção 
Rev. Interd. em Cult. e Soc. (RICS), São Luís, v. 7, n. 1, p. 14- 27, jan./jun. 2021 ISSN eletrônico: 2447-6498

de lugar, seja ele físico ou imaterial. Em contrapartida, o fator primordial nos estudos de Halbwachs abrange a noção de espaço pertinente à configuração dos grupos sociais, as memórias que estão conservadas no âmbito que ultrapassa as barreiras meramente geográficas.

Diante disso, o espaço é sempre habitado por um conjunto de memórias, de modo que esta é balizada a partir da experiência, dos símbolos que duram no tempo e no espaço (HALBWACHS, 2006). Essa concepção agrega sentido ao que é colocado no cerne das discussões sobre a duração da memória, de como as experiências podem ser conservadas através do contato com o lugar, enquanto elemento condicionante à rememoração.

A lógica da percepção dos grupos, de todos os objetos e estruturas que o cercam é delineada na amplitude da ideia de sociedade, dos agentes integralizadores dessa abstração, que é materializada por razão de suas relações internas. Conforme a prerrogativa, o indivíduo, enquanto ser resultante dessa sociedade, recorre ao passado para buscar entender os rumos de sua história, os precedentes que o levaram até o momento presente.

A memória é recuperada de acordo com as circunstâncias e acontecimentos, nos quais novas ideias acabam sendo transformadas, bem como sua impressão dos fatos, marcando a temporalidade e localizando dada recordação a partir de um marco (HALBWACHS, 2004). Essa reconstrução da memória pode trazer novas perspectivas e olhares para o grupo, de tal modo que podem ser agrupadas características adquiridas ou mesmo uma sensação de não pertencimento ao grupo considerado de origem, em face, sobretudo, da modificação do espaço.

Es un espacio inédito y um nuevo momento que se agregran a nuestro tempo y espacio, es un nuevo aspecto de nuestro grupo el que nos lo permite percibir desde una perspectiva diferente. Lo que conduce a un trabajo de adaptación permanente que nos obliga, en la circunstancia de cada acontecimiento, a regresar sobre el conjunto de nociones elaboradas de acontecimientos passados. (HALBWACHS, 2004, p. 163)

O ser sensível para Halbwachs é aquele que se configura pela experiência imediata, corroborando com uma ideia de carregar consigo as memórias/recordações através de uma situação vivida, num período fixado no tempo. O contato com novas percepções, consolidadas no tempo e espaço, traduz uma espécie de adaptação. A memória faz parte de uma impressão sobre o fato e, notadamente, sobre o indivíduo, ao passo que ao rememorar acaba refletindo sobre si mesmo e regressando a um conjunto de noções elaboradas do passado (HALBWACHS, 2004). 
Rev. Interd. em Cult. e Soc. (RICS), São Luís, v. 7, n. 1, p. 14- 27, jan./jun. 2021 ISSN eletrônico: 2447-6498

Os aspectos provenientes da memória são operados a partir de elementos que fomentam a recomposição dos dados recordados, em decorrência da articulação de pensamentos alicerçando a reconstituição do vivido. O espaço compreende a projeção das imagens e das relações estáveis com base nos sujeitos que o compõem, ou seja, não é possível poder falar da noção de memória coletiva que não seja desenvolvida e articulada dentro de um quadro espacial.

\begin{abstract}
Quando inserido numa parte do espaço, um grupo o molda à sua imagem, mas ao mesmo tempo se dobra e se adapta a coisas materiais que a ela resiste. O grupo se fecha no contexto que construiu. A imagem do meio exterior e das relações estáveis que mantém com este passa ao primeiro plano da ideia que tem de si mesmo. Essa imagem penetra em todos os elementos de sua consciência, deixa mais lenta e regula sua evolução. Não é o indivíduo isolado, é o indivíduo enquanto membro do grupo, é o grupo em si que, dessa maneira, permanece sujeito à influência da natureza material e participa de seu equilíbrio. (HALBWACHS, 2006, p. 159)
\end{abstract}

Tendo como referência essa compreensão da importância do espaço no campo da memória, é perceptível que nada permanece no espírito, mas no meio, mantendo assim, uma realidade que dura, firmada no grupo. Com isso, Guedes Júnior (2011, p. 4) em Entre o tempo e o espaço: cidade e memória social, expõe que "para Maurice Halbwachs essa apropriação do espaço acontece quando os pensamentos e as ações dos indivíduos se vinculam às imagens exteriores, ou seja, quando há a sedimentação dos hábitos dos indivíduos à materialidade que os cerca".

A recordação está atrelada aos constituintes da subjetividade coletiva, ao mesmo tempo que é evidenciada como reflexo de uma sociedade em sua esfera plural, adensando uma conjuntura de unidade dentro das multiplicidades existentes em seu contexto.

Quando tocamos na época em que já não conseguimos imaginar os lugares, nem mesmo confusamente, chegamos também a regiões do passado que nossa memória não atinge. Portanto, não é exato dizer que, para lembrar, é preciso que nos transportemos em pensamento fora do espaço, pois ao contrário é justamente a imagem do espaço que, em função de sua estabilidade, nos dá a ilusão de não mudar pelo tempo afora e encontrar o passado no presente - mas é exatamente assim que podemos definir a memória e somente o espaço é estável o bastante para durar sem envelhecer e sem perder nenhuma de suas partes. (HALBWACHS, 2006, p. 189)

Os caminhos que perpassam a dinâmica da memória proporcionam uma reflexão sobre o modo com o qual o ser sensível/racional opera com os marcos existentes. As lembranças que permeiam o presente são construídas com base nas experiências provenientes do grupo a que se pertence, bem como pela forma como o indivíduo o integra. Essas lembranças 
Rev. Interd. em Cult. e Soc. (RICS), São Luís, v. 7, n. 1, p. 14- 27, jan./jun. 2021 ISSN eletrônico: 2447-6498

coadunam com o conjunto de memórias que habitam no espaço, dialogando com as transformações e atrelados aos símbolos que perduram nessa conjuntura substancial.

Conforme a reflexão de Halbwachs (2006, p. 159), ao dizer que "o lugar ocupado por um grupo não é como um quadro-negro no qual se escreve e depois se apaga números e figuras", é compreensível que o espaço corrobora com uma estrutura muito além da composição de imagens soltas. Ao contrário disso, sua concepção traduz uma consciência pautada na busca pelos elementos integrativos de relações respaldadas por uma memória essencialmente coletiva, firmada em intensidades distintas, mas agregando um sentimento de pertencimento e reconhecimento de si.

O caráter memorialístico é depreendido pela ação prática exercida pelo sujeito que tem contato com suas experiências de outrora, a noção espacial acaba exercendo assim, uma atividade de reconstrução de algo dado como inacabado. Para que a memória seja reconstituída em sua totalidade, ela antes permeia o campo dos traços da singularidade, buscando reunir os fragmentos que se completam a partir das relações entre o espaço e os seres que transitam nele, seja de maneira indireta ou através de um mergulho profundo das reminiscências que necessitam de esclarecimento.

\section{CONSIDERAÇÕES FINAIS}

A experiência discente por meio do PROCAD, veio a somar com o conhecimento adquirido ao longo do tempo sobre a memória. Todavia, foi de suma importância o contato mais aprofundado com os fundamentos que integram a dinâmica composicional dos teóricos em estudos, a saber Bergson e Halbwachs. Cada um deles apresenta sua visão acerca dos processos que regem a experiência rememorativa, explicitando formas particulares de abordagem permitindo a reflexão crítica.

Num primeiro momento, os estudos propostos por Bergson quanto à memória sugerem uma transformação, sobretudo, no que se refere ao tratamento dos aspectos fomentadores da percepção das imagens, tendo em vista sua constância e a perspectiva da heterogeneidade, o que fundamenta a concepção do teórico. Esse movimento, assim, é representativo de processos de cunho extensivos, afetuosos e evolutivos, nos quais a matéria sempre ganha destaque devido a sua importância e ao seu caráter de imanência.

A memória parte do princípio do movimento como interação, e não como relatividade. A matéria cumpre seu papel disposta como algo fluente, logo, acaba sendo depreendida como um conjunto de imagens móveis. As coisas que estão no espaço assumem um papel de 
Rev. Interd. em Cult. e Soc. (RICS), São Luís, v. 7, n. 1, p. 14- 27, jan./jun. 2021 ISSN eletrônico: 2447-6498

temporalidade, mas acabam coexistindo apesar das diferenças entre si, a partir do chamado monismo do tempo.

Nesse viés, a imagem também pode ser entendida como uma memória, pois apresenta a capacidade de reconstruir os acontecimentos que são conservados no tempo, sendo traçados através da subjetividade. A realidade assume o compromisso de filtrar as informações que são consideradas necessárias, atendendo aos interesses dessa relação intrínseca entre passado e presente.

Em seguida, Halbwachs oportuniza um diálogo entre os aspectos fomentadores de uma realidade que tem como norte o entendimento do eu, entrelaçando, nesse contexto, o conjunto de experiências desenvolvidas na sociedade, compreendida na visão dos grupos. $\mathrm{O}$ arranjo material que envolve o espaço acaba servindo como subsídio para essa representação, e a linguagem assume um papel de mantenedora de uma história através da tradição, das informações repassadas de geração em geração, bem como dos aspectos que são singulares ao indivíduo, tido como ser sensível/racional.

Os símbolos que caracterizam essa memória são presentificados como balizadores de tudo aquilo que remete ao passado, em virtude de os marcos de referências possuírem relação intrínseca ao espaço, sendo atenuante ao próprio sujeito. Nesse viés, a espera de um equilíbrio que advém desse enfoque ocorre por meio da junção dos estilhaços deixados pela memória, abrigando as vivências de um tempo que ecoa fortemente na mente daqueles que transitam na esfera social.

A configuração dada à memória, em razão da linguagem e do espaço, demonstra que a adaptação em meio às transformações são inevitáveis, porém as recordações instituídas nesse ínterim são representativas da capacidade de assimilar as situações desenvolvidas num plano que ultrapassa a temporalidade. O passado acaba sendo refletido no presente, em face das marcas que este vai deixando em seu decurso, como uma realidade duradoura que se mantém fixada em correspondentes concentrados numa concepção interativa.

Contudo, é notório perceber que, tanto Bergson quanto Halbwachs, tratam a memória como um elemento de fundamental importância para o indivíduo, seja em sua forma individualizada (mais íntima e interior do ser) ou plural (a noção de coletividade). As lembranças sempre são equivalentes a um momento, um tempo, um espaço ou relações mantidas consigo e/ou com outros seres. O fator preponderante de cada teoria abordada parte, então, da realização, ou seja, a maneira como o ato rememorativo é concebido. De tal modo, como a memória deixa impressões no ser, como esta é consolidada em meio a tantos outros aspectos que são determinantes no universo de cada indivíduo. 
Rev. Interd. em Cult. e Soc. (RICS), São Luís, v. 7, n. 1, p. 14- 27, jan./jun. 2021 ISSN eletrônico: 2447-6498

\section{REFERÊNCIAS}

BERGSON, Henri. Matéria e Memória: ensaio sobre a relação do corpo com o espírito. Tradução de Paulo Neves. 2. ed. São Paulo: Martins Fontes, 1999.

DELEUZE, Gilles. Bergsonismo. Tradução de Luiz B. L. Orlandi. São Paulo: Editora 34, 1999.

GUEDES JUNIOR, Antonio Fernando Cordeiro. Entre o tempo e o espaço: cidade e memória social. In: SIMPÓSIO NACIONAL DE HISTÓRIA, 26, 2011, São Paulo, Anais [...]. São Paulo: ANPUH, jul. 2011.

GUIMARÃES, Joaquim Francisco Soares et. al. O conceito de memória na obra "Matéria e Memória", de Henri Bergson. In: COLÓQUIO INTERNACIONAL "EDUCAÇÃO E CONTEMPORANEIDADE", 6, 2012. São Cristóvão, SE, Anais [...], São Cristóvão: Educom, UFS, 2012.

HALBWACHS, Maurice. A memória coletiva. São Paulo: Centauro, 2006.

HALBWACHS, Maurice. Los marcos sociales de la memoria. México: Anthropos, 2004.

RIVERA, Dario Paulo Barrera. Linguagem, memória e religião no pensamento de Maurice Halbwachs. Horizonte, Belo Horizonte, v.16, n.51, p.1177-1196, set./dez. 2018. 